
\title{
28 Research Suare \\ Prediction of Pasture Intake by Beef Cattle in Tropical Conditions
}

\section{Geferson Antonio Fernandes}

UFMT: Universidade Federal de Mato Grosso

André Soares de Oliveira

UFMT: Universidade Federal de Mato Grosso

Cláudio Vieira de Araújo

UFMT: Universidade Federal de Mato Grosso

Victor Rezende Moreira Couto

UFMT: Universidade Federal de Mato Grosso

Kamila Andreatta Kling de Moraes

UFMT: Universidade Federal de Mato Grosso

Eduardo Henrique Bevitori Kling de Moraes ( $\nabla$ nepi@ufmt.br)

Universidade Federal de Mato, Campus Universitário de Sinop https://orcid.org/0000-0001-8634-6675

\section{Research Article}

Keywords: meta-analysis, modeling, tropical pasture, supplementation

Posted Date: July 7th, 2021

DOl: https://doi.org/10.21203/rs.3.rs-657735/v1

License: (c) (i) This work is licensed under a Creative Commons Attribution 4.0 International License.

Read Full License

Version of Record: A version of this preprint was published at Tropical Animal Health and Production on December 13th, 2021. See the published version at https://doi.org/10.1007/s11250-021-03018-1. 


\section{Abstract}

A meta-analytic study was conducted to develop and evaluate models for the prediction of pasture dry matter intake ( $\left.\mathrm{DMI}_{\text {pasture }}\right)$ by beef cattle in tropical conditions. 804 individual observations of $\mathrm{DMI}_{\text {pasture }}$ were used, taken from 23 studies through analysis of mixed models, including the study as a random effect. To evaluate the accuracy and precision of the new models proposed as well as for the models of Azevedo et al., (2016) and Minson and McDonald (1987), an independent databank with 87 means from treatments of 21 experiments ( $n=888$ animals) was used. Three prediction models were adjusted: Model I (Animal Information), Model II (Animal Information + Supplement) and Model III (Animal Information + Supplement + Pasture). The proposed models presented similarity for the average square root of the prediction error. The inclusion of the predictive variables for supplementation (supplement dry matter intake - $\mathrm{DMI}_{\text {supplement }}$ \% of the body weight and crude protein intake through supplement) with the variables for the animal (BW ${ }^{0,75}$ and average daily gain) and of the pasture (\% of crude protein) in Model III improves accuracy and precision and provides higher determination and correlation coefficients, and agreement than the other proposed models. Similarly, it was found to be more accurate and precise than the equations of Azevedo et al., (2016) and Minson and McDonald (1987), which presented lower precision and accuracy than the proposed models. The $\mathrm{DMI}_{\text {pasture }}$ for beef cattle in tropical conditions is more accurate and precise when the information for the animal, supplement and pasture is included.

\section{Introduction}

Production systems in pasture present difficulties in terms of the formulation of diet due to the complexity of predicting pasture intake and consequently, the quality of the material consumed. In this sense, the formulation of diet for beef cattle raised in a supplement-pasture system has taken place in an empirical manner.

For the formulation of the supplements, the pasture should be considered as a base ingredient and the supplements should complement the nutrients missing from the pasture so that the nutritional requirements of the animals are met. In this way, to allow for the efficient planning of supplementation programs that permit better planning of feeding and satisfaction of nutritional requirements, it is necessary to precisely and accurately predict the pasture dry matter intake ( $\left.\mathrm{DMI}_{\text {pasture }}\right)$.

In cattle production systems with pasture, the variables that influence the $\mathrm{DMI}_{\text {pasture }}$ are numerous, many of them hampering the meeting of the nutritional requirements of the animals. According to Azevedo et al. (2016), the greater part of the nutrients in the beef cattle diet are used to supply the requirements of maintenance while a small portion contributes toward weight gain. Therefore, when small alterations occur in dietary intake, limitations in the efficacy of the productive processes result, leading to a slower growth rate, and increasing production costs.

Determining the $\mathrm{DMI}_{\text {pasture }}$ precisely is not an easy task. Coleman et al. (1999) affirms that intake is altered as a function of both the quality and the physical characteristics of the forage, as well as due to 
the physiological state of the animal. In addition to these related factors, intake by cattle can be influenced by the use, or not, of dietary supplements, varying according to the nutritional level and composition of the available food.

Therefore, if a given model does not adequately estimate the $\mathrm{DMI}_{\text {pasture }}$ of an animal, these factors can compromise the productive process, leading to liabilities for the producer and even rendering the agricultural activity unfeasible. In this sense, the models should be developed to predict, with greater precision and accuracy, the intake by cattle raised in pasture conditions.

However, the majority of the models to estimate the dry matter intake (DMI) of beef cattle are adjusted with data from animals in confinement using variables related to the animal, such as the body weight (BW) and average daily gain (ADG). However, the variables that influence intake in systems based on pasture are more heterogeneous than in confinement, which explains the need to develop new models to be applied for animals raised on pasture and to include the variables related to the animal and their diet.

Therefore, our hypothesis is that more complete equations, that include variables associated with the animal, supplements and pasture, better predict the $\mathrm{DMI}_{\text {pasture. }}$. As such, we sought to develop and evaluate predictive models for $\mathrm{DMI}_{\text {pasture }}$ for beef cattle.

\section{Material And Methods}

\section{Data bank and development of models:}

The data set used to formulate the predictive models was obtained from individual observations reported in 23 studies carried out under tropical conditions between 2006 and 2019, totaling 104 means of treatment that represented 804 sample animals (growth or finishing).

The criteria adopted for inclusion of data in the set were: 1) experiments carried out under tropical conditions; 2) cattle fed using different feeding management systems and different production levels; 3 ) individual measures of $\mathrm{DMl} ; 4$ ) estimate of $\mathrm{DMI}_{\text {pasture }}$ using external and internal markers; 5) adequate description of the animals: $B W, D M I, A D G$, experimental diets: ingredients and chemical composition. The data used were from Zebu cattle (male and female).

The experiments included in the data bank for the elaboration of the models were realized at different times of the year (dry, dry-wet transition, wet and wet-dry transition). They were carried out using an entirely randomized design. The pastures were divided into different paddock with drinking fountains and covered feeders, and a wide variety of treatments, using different supplement amounts and compositions.

The descriptive statistics (average, median, maximum and standard deviation) for all the variables used in the development of the predictive equations for $\mathrm{DMI}_{\text {pasture }}$ are found in Table 1. 
For the inclusion of the independent variables into the model, the Pearson linear correlation coefficients (Table 3 ) were determined. For the variable to remain in the model, the procedure of elimination of non-significant independent variables $(P>0.05)$ was applied, with the reduced models that best explained the evaluated dependent variable being kept (Neter et al., 1990). The observations that presented studentized residuals larger than 2.5 or smaller than -2.5 were discarded from the data bank used for the formulation of the models.

The development of the proposed predictive models was adjusted using an analysis of the mixed models on the Rsudio software, version 3.6.2, including the study as a random effect in the models.

\section{Evaluation in the Models}

To evaluate the accuracy and precision of the proposed models, as well as for the models of Azevedo et al., (2016) (https://brcorte.com.br/livro2016en) and Minson and McDonald (1987), an independent data bank was used, with 87 observations (means of treatments) originating from 21 experiments carried out under tropical condition ( $n=888$ animals) composed of male and female (Zebu cattle), following the same selection criteria for data selection to adjust the equations.

A literature research was carried out using the data bank of [Web of Science https://login.webofknowledge.com), PubMed (https://www.ncbi.nlm.nih.gov/pubmed), Google Sholar (http://www.scholar.google.com), Scielo (https://scielo.org/). (Appendix A).

The evaluation of accuracy and precision of the models developed and of those already in the available literature (Table 3) were realized by way of analyses of simple linear regression of the observed $(\mathrm{Y})$ and predicted $(\mathrm{X})$ values, using the following procedures: graphic analysis of the observed versus predicted values, coefficient of determination, MSPE (mean square prediction error), RMSPE (root MSPE) and CCC (concordance correlation coefficient) analyses using the Model Evaluation System (College Station, TX;http://nutritionmodels.tamu.edu/mes.html), as described by Tedeschi (2006).

The MSPE was broken down into three sources of error: 1) Errors due to bias, the most accurate model is the one with an average bias close to the value $0 ; 2$ ) Errors due to the deviation of the regression between the observed and predicted values being different from 1; and 3) Random error. The random error represents the error that is unexplained by the model (Bibby and Toutenburg, 1977)

The MSPE is frequently used to verify the accuracy of the model. According to Wilks (2006), by elevating the individual differences to the square root, it always becomes positive, where MSPE $=0$ indicates a perfect prediction.

In addition to the MSPE, RMSPE is commonly used to express the accuracy of the results, with the advantage that it presents values for the error in the same dimensions of the analyzed variable. The values were expressed in $\mathrm{kg} /$ day and in \% of the observed $\mathrm{DMI}_{\text {pasture, }}$ and their confidence interval by error type I of $5 \%$, according to the proposal of Vieira (2017). 
The CCC was divided into correlation coefficient, indicating the $\rho$ and the factor of bias correction, indicating the bias correction factor ( $\mathrm{Cb}$ - accuracy). The correlation coefficient estimate ( $\rho$ - precision) and $\mathrm{Cb}$ values varied from 0 to 1 , with values close to 1 indicating greater precision and exactitude (Lin, 1989; King and Chinchilli, 2001; Liao, 2003).

The descriptive statistics (average, median, minimum, maximum and standard deviation - SD), for all the variables used in the predictive equations of the $\mathrm{DMI}_{\text {pasture }}$ can be found on Table 2 .

\section{Results}

\section{Data bank}

The data bank used to develop (Table 1) and evaluate (Table 2) the models of the $\mathrm{DMI}_{\text {pasture }}$ represented an ample range of the characteristics of the beef cattle and the diets used. Additionally, the data set was representative of the beef cattle systems, which used alimentary supplementation during the growth phases of the animals.

For adjustment and evaluation of the models, the descriptive statistics of the animals and the diets used were close, indicating that the two subsets were adequate (Tables 1 and 2) for model development and evaluation. The same evaluation process was applied in the models already published.

\section{Development of the predictive models}

In the three models proposed for $\mathrm{DMI}_{\text {pasture }}$ the variables associated with the animal, the supplements and pasture (Table 4$)$ were adjusted $(P<0.05)$. In Model I, the metabolic body weight $\left(B W^{0,75}\right)$ and $A D G$ were adjusted $(P<0.05)$. In Model II, in addition to the variables of Model I, information related to the supplement $\left(\mathrm{DMI}_{\text {supplement }}-\% \mathrm{BW}\right)$ and $\mathrm{CPI}$ supplement $(\mathrm{kg} /$ day $)$ was adjusted $(\mathrm{P}<0.05)$. In Model III, the variables from Model II as well as information related to pasture (\% of CP) were adjusted $(P<0.05)$.

The NDF presented a low correlation with $\mathrm{DMI}_{\text {pasture, }}$ in addition to not presenting significance during the process of elimination of the non-significant independent variables. For this reason, it was not used for the adjustment of the models.

The effect of the study was considered as random in all the models, since according to St-Pierre (2001), when it is included in the analyses, the equations generated become more precise. The effect of race, sex and their interactions were tested, however significance $(P>0.05)$ was not observed in the analyses. Therefore, separate models were not proposed.

The proposed models I (Animal) and III (Animal + Supplement + Pasture) presented non-significant results for the line's intercept and slope $(P>0.05)$ (Table 5$)$ indicating that they could be used to predict 
the DMI pasture. However, Model II (Animal + Supplement), presented significant results for the line's intercept and slope $(\mathrm{P}<0.05)$, indicating that it is not adequate for the estimation of $\mathrm{DMI}_{\text {pasture}}$.

\section{Evaluation of the models}

The new models proposed were able to explain between 45 to $52 \%\left(R^{2}\right)$ of the variability between the predicated and observed values (Table 5). Model I presented the second lowest average bias for prediction (underestimated in $0.10 \mathrm{~kg} /$ day, Table 5, Figures 1 and 2), lowest accuracy $(\rho=0.68)$ and precision $(\mathrm{Cb}=0.85)$, leading to the lowest CCC (0.58). Additionally, it presented the lowest MSPE (1.37), and similar ( $P>0.05)$ RMSPE (24.32\% of observed DMI pasture) in comparison with Models II and III. The decomposition of the MSPE, indicated that this model presented a larger part of the uncorrelated errors, since the absence of correlation accounted for by random errors was $96.73 \%$ and the average bias was only responsible for $0.68 \%$ of the prediction errors.

Model II presented the lowest average bias $(0.08 \mathrm{~kg} / \mathrm{d})$, as well as intermediary precision $(\mathrm{Bc}=$ $0.84)$, and accuracy $(\rho=0.71)$, presenting the second best CCC $(0.60)$ in comparison with models I and III. In the process of partition of the MSPE, it presented the lowest participation of the random error (93.71\%) and the lowest error associated with average bias (0.53\%). However, it presented a significant effect $(P<0.05)$, for the line's intercept and slope, indicating that there was no similarity between the observed $\mathrm{DMI}_{\text {pasture }}$ and that predicted by the model.

Model III presented a prediction bias similar to that of Model I (underestimated by $0.10 \mathrm{~kg} / \mathrm{day}$ ), higher $\rho$ (0.72) and $\mathrm{Cb}(0.87)$ leading to higher $\mathrm{CCC}(0.63)$. It obtained the lowest MSPE (1.23), and similar ( $P>0.05)$ RMSPE (23.07\% of the observed DMI pasture) in comparison with Models I and II. With the decomposition of the MSPE it was found that this model presented a greater part of the non-correlated errors, given that the lack of correlation accounted for by the random error was $95.59 \%$ and the average bias was only responsible for $0.88 \%$ of the prediction error.

The model proposed by Azevedo et al. (2016) estimated DMI pasture with greater average bias $(-0.290 \mathrm{~kg} / \mathrm{d})$, lower CCC (0.52), $\rho$ (0.53) and $\mathrm{Cb}(0.98)$ and higher ( $\mathrm{P} \leq 0.05)$ RMSPE (33.98\% of the observed $\left.\mathrm{DMI}_{\text {pasture }}\right)$, than the models proposed. It presented a significant result $(P<0.05)$ for the intercept and slope of the line, indicating a difference between the observed and predicted.

The model proposed by Minson and Mc Donald (1987) presented higher average bias $(-0.790$ $\mathrm{kg} / \mathrm{d})$, lower $\rho(0,65)$ and $\mathrm{Cb}(0.78)$ that led to lower CCC $(0.50)$. Additionally, it presented higher $(P \leq 0.05)$ RMSPE (29.73\% of the observed $\left.C_{\text {pMasture }}\right)$, than the models proposed.

\section{Discussion}


The prediction of $\mathrm{DMI}_{\text {pasture }}$ is complex and dependent on various factors. Coleman et al. (1999) found that the $\mathrm{DMl}_{\text {pasture }}$ varies as a function of the quality and physical characteristics of the forage and is inherent to the physiological state of the animal, as well as to environmental conditions. In this manner, the interactions to be considered as estimates for prediction are more complex than for animals fed in a feedlot system (Azevêdo et al., 2016).

When analyzing the coefficient of determination provided by the models proposed for the $\mathrm{DMI}_{\text {pasture, }}$ it was found that they did not present high values. However, it would be wrong to say that a non-elevated $\mathrm{R}^{2}$ indicates low correlation between the predicted and observed values, given that this relation can be curvilinear (Tedeschi, 2006). In these cases, submitting the data to further analysis, to verify the accuracy and precision between the predicted and observed values becomes necessary.

In this context, it was found that Models I and III presented close results without difference for RMSPE, indicating that both models are adequate to predict the $\mathrm{DMI}_{\text {pasture. }}$. Despite Model II had lower average bias than Models I and III, it presented an intercept different to zero and the slope was different from the unity, and indicates that the relationship between observed and predicted $\mathrm{DMI}_{\text {pasture }}$ was not adequate. Therefore, its use is not recommended.

In addition to the RMSPE, other measures have been employed to evaluate the models, since the evaluation should be based on diverse measures that evaluate precision, accuracy and adequation. The CCC, which is an index of reproducibility, simultaneously considers the exactitude and precision of the model. In this context, Model III presents better adjustment to estimate the $\mathrm{DMI}_{\text {pasture }}$ given that it showed higher CCC than the other models.

Generally, Model I provided acceptable prediction for $\mathrm{DMI}_{\text {pasture. }}$. However, given that this model was similar to Model III for average bias and RMSPE, but presented lower CCC, its utilization was limited. Therefore, the hypothesis that the use of more complete models, which include variables associated with the animal, supplements and pasture, better predicts the $\mathrm{DMI}_{\text {pasture, }}$ was confirmed. By presenting the proximity of the RMSPE with Model I, higher CCC and lower average bias, Model III can be considered the most adequate for prediction of $\mathrm{DMI}_{\text {pasture }}$.

Although the equation proposed by Azevedo et al., (2016) had been developed using observation of beef cattle raised on pasture, the quality of its prediction for the $\mathrm{DMI}_{\text {pasture }}$ was inferior to that of the new models proposed and to the equation of Minson and McDonald (1987). Additionally, this model presented a significant result for the line's intercept and slope $(P<0.05)$, being found to be inadequate for the prediction of $\mathrm{DMI}_{\text {pasture }}$.

However, it is worth noting that the equation proposed by Azevedo et al. (2016), was developed to estimate the total CDM and not just $\mathrm{DMI}_{\text {pasture, }}$ which may have led to a lower predictive capacity and a significant result for the line's intercept and slope $(P<0.05)$, indicating a lack of adequacy between the predicted and observed $\mathrm{DMI}_{\text {pasture. }}$ 
The equation proposed by Minson and McDonald (1987) did not adequately estimate $\mathrm{DMI}_{\text {pasture. }}$. Despite the intercept between the predicted and observed $\mathrm{DMI}_{\text {pasture }}$ values not being different from zero and the slope not being different from the unity, this equation explained $41 \%$ of the variation of the $\mathrm{DMI}_{\text {pasture }}$ and overestimated intake by $16.4 \%$. Additionally, it presented a lower CCC and little participation by the random error during the partition of the MSPE of all the adjusted models.

This lower predictive capacity can be associated with the non-inclusion of the variables related to the supplements and pasture consumed by the animals. This fact may have diminished the quality of the prediction, which is similar to what was observed for the proposed Model I, which only included variables related to the animal, and which also presented a lower predictive capacity than the more complete model containing variables related to the animal, supplement and pasture.

Heat stress can cause a reduction in the intake of the animals leading to a negative impact on performance (West, 2003). However, due to the majority of the studies published not reporting variables related to climatic conditions, its inclusion in the adjustment of the models, which could improve the prediction, was not possible. However, when the environmental conditions are outside the zone of thermal comfort due to an increase in air temperature or the temperature-humidity index, the $\mathrm{DMI}_{\text {pasture }}$ and efficiency of feeding drop significantly (West, 2003).

Through the results obtained, it is possible to observe the greater complexity of the factors that affect the DMI in beef cattle systems based on pasture, in addition to the greater challenge in predicting this variable under these conditions. This demonstrates that there are other factors beyond those evaluated in this study that should be identified and added to future predictive models.

Two main factors that help to explain the greater difficulty in predicting $\mathrm{DMI}_{\text {pasture }}$ can be highlighted: 1) the greater complexity of the factors that affect ingestion, such as availability of forage, and the structural and morphogenic characteristics of the pasture, (Stobes, 1973; Carvalho et al., 2007); 2) Difficulties in measuring the $\mathrm{DMI}_{\text {pasture }}$ under grazing conditions due to the grazing tests frequently not taking the selection of the diet into account, as well as the representativity of the pasture sample effectively consumed by the animals (Lopes, 2008).

The selectivity of the animal can negatively influence the $\mathrm{DMI}_{\text {pasture }}$ since the animal uses a greater part of its time searching for better quality food (Cosgrove, 1997). Further, when the animal encounters some type of limitation in grazing on the pasture and/or low availability of pasture, there is an increase in the chew rate and grazing time, which ends up interfering in the $\mathrm{DMI}_{\text {pasture, }}$ a variable which is also complex when included in the predictive models.

\section{Conclusion}

The new models proposed presented greater accuracy and precision for the prediction of pasture dry matter intake than the models of Azevedo et al., (2016) and Minson and McDonald (1987). 
Reggarding the new models proposed, the use of Model III is recommended, which includes information on the animal, supplement and pasture.

\section{Declarations}

Authors' contributions: The study was designed by EHBKM and GAF. Formal analysis and investigation: GAF and ASO. Statistical analyses: GAF and CVA. Writing - original draft preparation: GAF. Writing - review and editing: EHBKM and KAKM.

Funding: No funding

Availability of data and material: The data that support the results of this study are available from the corresponding author upon reasonable request.

Ethics approval: Not applicable

Code availability: Not applicable

Consent to participate: Not applicable.

Conflicts of interest: The authors declare no conflicts of interest.

\section{References}

1. Azevêdo, J.A.G., Valadares Filho, S.C., Costa e Silva, L.F., R. P. Polyana, Rennó, L. N., Prado, I. N. 2016. Regulation and prediction of dry matter intake. In: VALADARES FILHO, S. DE C. et al. (Ed.). Nutrient requirements of zebu and crossbred cattle - BRCORTE. 3. ed. Viçosa, MG: Editora Federal de Viçosa, p. $15-42$.

2. Bibby, J., D. and H. Toutenburg. 1977. Prediction and improved estimation in linear models. John Wiley \& Sons, Berlin, Germany.

3. Carvalho, P.C.F.; Kosloski, G.V.; Ribeiro Filho, H.M.N.; Reffatti, M.V.; Genro, T.C.M.; Euclides, V.P.B. 2007. Avanços metodológicos ne determinação do consumo de ruminantes em pastejo. Rev. Bras. Zootec, v.36, suplemento especial, p.151-170.

4. Coleman, S. W.; Lippke, H.; Gill, M. 1999. Estimating the nutritive potential of forages. In: Jung, H. G., Fahey Jr., C. G. (Ed.) Nutritional ecology of herbivores: Proc. Vth Int. Symp. Nutr. Herbivores. Am. Soc. Anim. Sci., Savoy, IL, 647-695.

5. Cosgrove, G. Grazing behaviour and forage intake. 1997. In: Simpósio internacional sobre produção animal em pastejo, 1. Viçosa, MG. Anais... Viçosa, MG: UFV, 1997. p. 59-80.

6. King, T. S., and V. M. Chinchilli. 2001. Robust estimator of the concordance correlation coefficient. J. Biopharm. Stat. 11:83-105.

7. Liao, J. J. Z. 2003. An improved concordance correlation coefficient. Pharm. Stat. 2:253-261. 
8. Lin L. I. K. 1989. A concordance correlation coefficient to evaluate reproducibility. Biometrics. 45: 255-268.

9. Lopes, F. C. F. 2008. Consumo de forrageiras tropicais por vacas em lactação sob pastejo em sistemas intensivos de produção de leite. Cadernos Técnicos de Veterinária e Zootecnia, v. 57, p. 67117.

10. Minson, D. J. and McDonald, C. K. 1987. Estimating forage intake from the growth of beef cattle. Trop. Grassl. 21: 116-122.

11. Neter, J.;W. Wasserman, M.H. Kutner. 1990. Applied Linear Statistical Models. 3 ed. Homewood, IL.

12. Stobs, T. H. 1973. The effect of plant structure on the intake of tropical pastures. I - Variation in the bite size of grazing cattle. Aust J Agric Res, v.24, p.809- 819

13. St-Pierre, N. R. 2001. Invited review: Integrating quantitative findings from multiple studies using mixed model methodology. J. Dairy Sci, 84:741-755.

14. Tedeschi, L. O. 2006. Assessment of the adequacy of mathematical models. Agric. Syst. 89:225-247.

15. Vieira, F.J.G. 2017. Fatores que afetam o consumo de matéria seca de vacas leiteiras. (Dissertação Mestrado em Zootecnia). Universidade Federal de Mato Grosso - Sinop, 81p.

16. West, J. W. 2003. Effects of heat-stress on production in dairy cattle. J. Dairy Sci. 86:2131-2144.

17. Wilks, D. S. 2006. Statistical Methods in the Atmospheric Sciences. International Geophysics Series. 2a. Edição, Estados Unidos da América, Academic Press, v. 91, 627 p.

\section{Tables}

Due to technical limitations, table 1-5 is only available as a download in the Supplemental Files section.

\section{Appendix}

Appendix A is not available with this version.

\section{Figures}



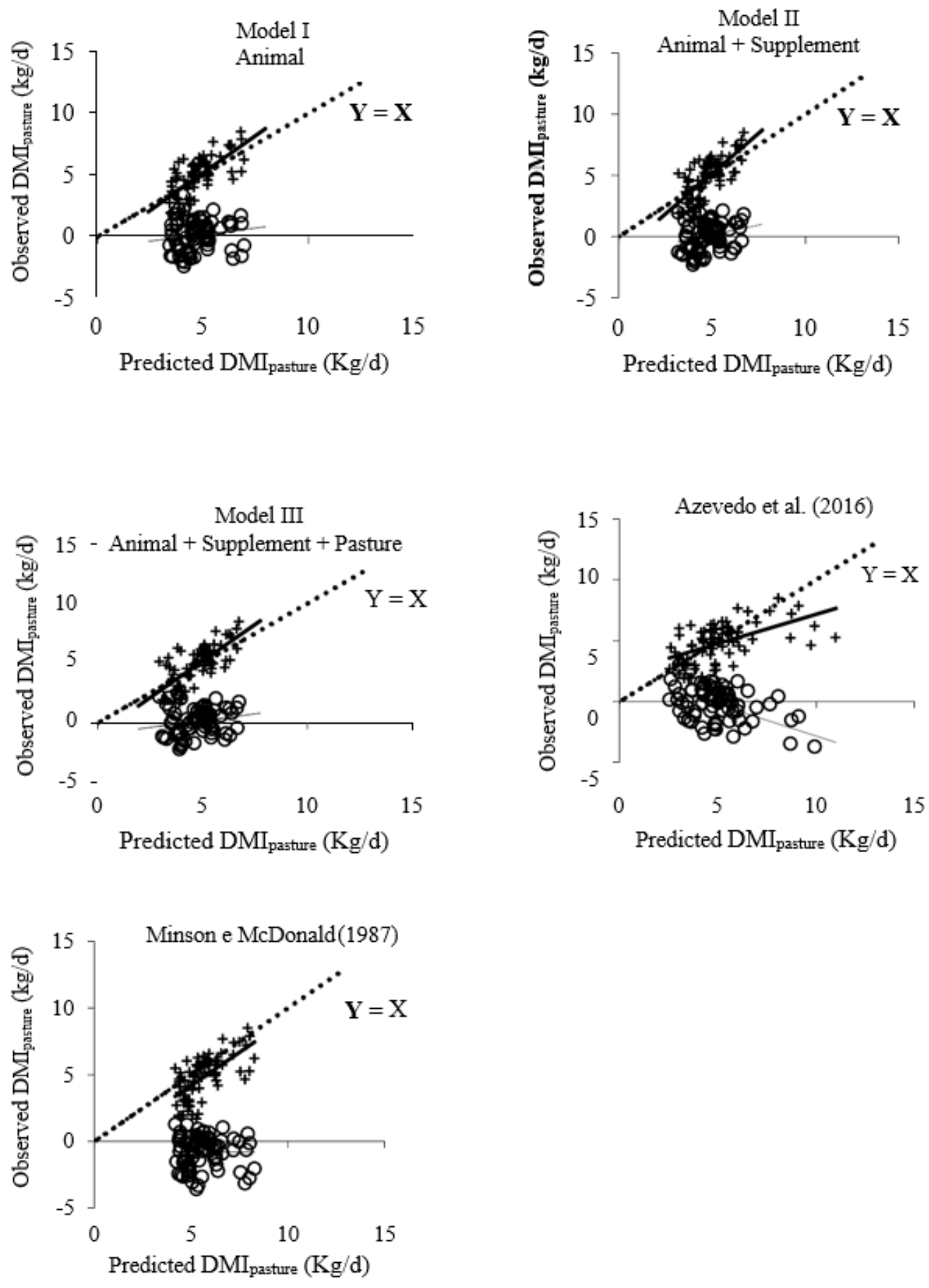

\section{Figure 1}

Relationship between observed (asterisk) and residual (observed - predicted; circles) DMlpasture values, with predicted DMI values for beef cattle under grazing system using Models I (Animal), II (Animal + Supplement), III (Animal + Supplement + Pasture) 


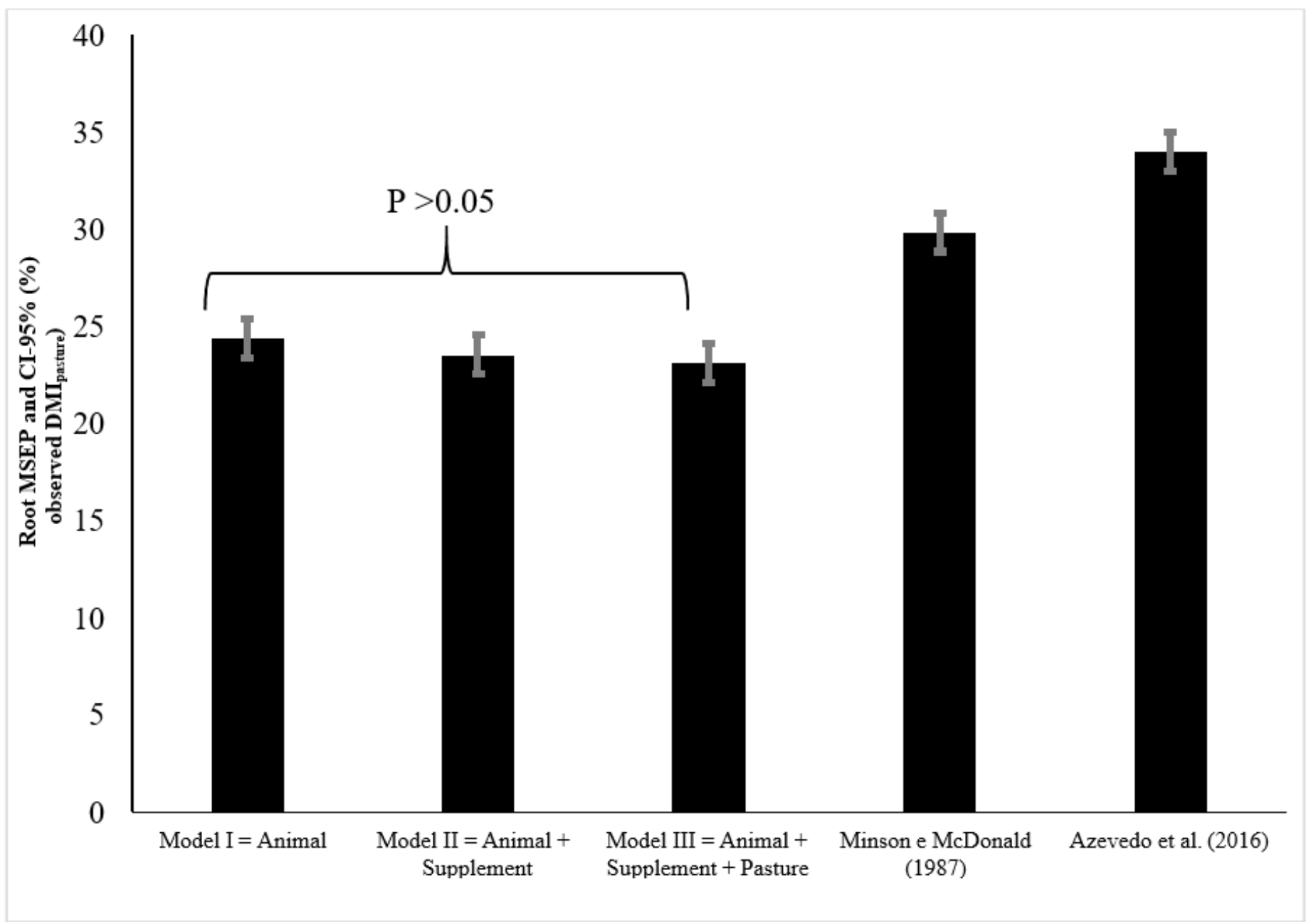

Figure 2

Values of the mean square root of the prediction error (MSPE) and its confidence interval $(95 \% \mathrm{Cl})$ of the predictive models of DMlpasture (Table 4) by beef cattle under tropical conditions

\section{Supplementary Files}

This is a list of supplementary files associated with this preprint. Click to download.

- TabelasCMSpasto.pdf 